\title{
Nosotros, vosotros, ellos: relatos de viajeros judíos del siglo XV a la luz del concepto de alteridad
}

\author{
María José Cano Pérez, Tania María García Arévalo** \\ Universidad de Granada
}

La literatura de viajes podría considerarse el nexo de multitud de tipos de textos dentro del género de la narrativa. Sin embargo, los datos que ofrece desde el punto de vista histórico, geográfico o sociológico, entre otros, hacen de ella un registro del que subyacen además las experiencias propias de los viajeros en sus travesías. De este modo, resultan especialmente destacadas en estudios de identidad en los que observar la alteridad que muestran los autores en sus escritos en los que describen, de manera constante, su percepción de los lugares que visitan pero también las diferentes comunidades, judías y no judías, con las que se encuentran. En estas páginas se ofrece un estudio acerca de las impresiones de autores medievales del siglo XV en sus viajes.

Palabras Clave: Literatura de viajes; viaje; otredad; Edad Media; identidad; comunidades; árabe; cristiano; Mešulam de Volterra; 'Obadiá de Bertinoro.

We, you, they: Writings of JeWish Travelers from 15th Century in the Light of the CONCEPT OF OTHERNESS: Travel literature could be considered as the nexus of numerous types of texts within the narrative genre. Nevertheless, the information it offers from historical, geographical or sociological, among others, points of view, converts it into a register from which are concealed the own experiences of travelers in their journeys. In this sense, these ones are specially relevant in identity studies in which it is possible to observe the alterity that the authors show in their writings describing, in a constant way, their perception of the places they visited but also different communities, Jewish and nonJewish, they find. In these pages it is offered a study about the impressions of 15 th-century Medieval authors in their voyages.

Keywords: Travelogue; Travel writing; Alterity; Middle Ages; Identity; Communities; Arabic; Christian; Meshullam of Volterra; Obadyah of Bertinoro.

"Este trabajo forma parte de los resultados del Proyecto «Edición y estudio de los escritos de viajeros judíos de Siria-Palestina (siglos XII-XVII)», concedido dentro del programa de Proyectos Precompetitivos (2014-2015) del Plan Propio de la Universidad de Granada.

***rimon@ugr.es, taniagarcia@ugr.es 


\section{INTRODUCCIÓN}

Antes de centrarnos en los relatos de los viajeros que ocuparán las siguientes páginas, es necesario que nos detengamos en la concepción que sobre el género de la literatura de viajes se ha guardado tradicionalmente para observar la naturaleza de los textos que ejemplificarán la alteridad partiendo de la percepción y visión de cada uno de sus autores.

El origen de este género se encuentra en la literatura geográfica que, a su vez, fue originada por la necesidad de los gobernantes de controlar a sus potenciales enemigos mediante el conocimiento de sus territorios y población. Después, lo que comenzaron siendo informes político-diplomáticos en los que se describían los territorios, sus accidentes geográficos, urbanístico-defensivos y antropológicos, evolucionó hacia una obra de literatura narrativa por efecto de la visión personal del informante. La llamada literatura de viajes recogía informes de exploraciones, obras de aventuras, documentos epistolares, etc., por lo que no era infrecuente que se encontrara inserta en obras de otros géneros tan diferentes como son las maqamas ${ }^{1}$, las obras historiográficas, e incluso obras como la Ilíada o la Odisea contienen relatos que se puede considerar bajo esta denominación dado que describen los territorios donde se desarrolla la narración ${ }^{2}$.

Por sus características híbridas, combinando diversos tipos de textos, su tipificación ha sido problemática ${ }^{3}$; sin embargo, existen puntos en común en todos los relatos de viaje que imprimen rasgos de un género

\footnotetext{
${ }^{1}$ Los más conocidos autores de maqamas (en plural /maqamāt/) fueron al-Hamadān̄̄ (967-1007), al-Harīiñ (1054-1122) y al-Harīzì (1170-1235). Todos ellos se dedicaron a estas composiciones literarias en prosa rimada con breves pasajes poéticos en forma de relatos con un narrador cuyo protagonista es un pícaro. Una completa obra sobre la historia de este género literario es la ofrecida por J. HämeEn-AnTtILA, Maqama: A History of a Genre (Wiesbaden 2002).

${ }^{2}$ Véase M. ${ }^{a}$ J. CANO PÉREZ, «La otredad en los libros de viajeros musulmanes y judíos en Siria-Palestina según Ibn Ŷubayr y Benjamín de Tudela», Miscelánea de Estudios Árabes y Hebraicos, Sección Árabe-Islam 63 (2014) págs. 5-20: 6.

${ }^{3}$ Véase M. B. CAmpbell, The Witness and the Other World: Exotic European Travel Writing, 400-1600 (London 1988) pág. 6; S. CERDA Montes DE OCA, «Viajes y escritura: recorrido y reflexión sobre la escritura de viajes y la tradición latinoamericana de la literatura de viajes», Lejana. Revista Crítica de Narrativa Breve 5 (2012) págs. 1-5: 1.
} 
propio $^{4}$. En primer lugar, guardan un centro narrativo que es la historia misma del viaje. En segundo lugar, poseen una ficcionalidad, esto es, la experiencia que supone para ellos el traslado y, por último, los eventos se narran en forma autobiográfica en su mayoría.

Estas tres particularidades anteriormente citadas estarán presentes asimismo en los relatos de Mešulam de Volterra y 'Obadiá de Bertinoro, los autores sobre cuyos textos estudiaremos la alteridad, la visión del otro en contraposición con el yo o el nosotros que se deriva de su percepción personal. Este hecho resulta relevante ya que la identidad de los viajeros no únicamente se forma con la afirmación de que profesan, en este caso concreto el judaísmo, sino que toman conciencia de sus similitudes y diferencias con otros grupos con los que se encuentran en su periplo a través del contacto con ellos. Desde el punto de vista de los estudios sociales, este tipo de aproximaciones a los textos suponen una fuente de conocimiento no únicamente en lo relativo a cuestiones históricas sino que, de otra manera, arrojan luz sobre la percepción que cada grupo social o religioso mantiene de los demás y que puede desviarse, o no, de unas concepciones previas a través de su contacto o convivencia con los mismos. El objetivo de estas páginas será ofrecer la impresión de estos viajeros sobre varias cuestiones y las similitudes o diferencias que se reflejan en sus textos que derivan, además, de su clase social e intencionalidad del viaje. Por otra parte, se proporcionarán otros textos de autores anteriores y posteriores a ellos como Benjamín de Tudela o Mošé Basola, cuyos viajes se datan en el siglo XII y XVI respectivamente, a manera de elementos comparativos con respecto a aquellos del siglo XV.

\section{El Viaje y SUS PRotagonistas. BREVES nOtas}

Al centrar nuestra atención en los dos viajeros referidos anteriormente, hemos de destacar que poseen un nexo común: el desplaza-

\footnotetext{
${ }^{4}$ Se recogen en B. KORTE, «Travel Narrative», en Routledge Encyclopedia of Narrative Theory, ed. D. Herman, M. Jahn y M.-L. Ryan (London 2010) págs. 619-620: 619, o de manera breve en S. CERDA, «Viajes y escritura», pág. 2. También B. Korte, English Travel Writing from Pilgrimages to Postcolonial Explorations (Basingstoke - New York 2000) aplicado a la literatura de viajes inglesa aunque propone la caracterización básica de este género de manera universal.
} 
miento desde Occidente a Oriente en el siglo XV pese a sus diferentes motivaciones. En cuanto a éstas, Mešulam de Volterra, procedente de una familia judía italiana originaria de la región de la Toscana, era un rico comerciante habituado a las comodidades que realizó viajes por el Mediterráneo, Egipto, Israel y Siria en 1481. Más allá de algún propósito religioso y espiritual, la intención comercial en él estaba siempre presente ya que uno de los puntos básicos en su viaje es la perspectiva económica de los lugares por los que pasa ${ }^{5}$. 'Obadiá de Bertirnoro, por su parte, fue uno de los más conocidos comentaristas de la Mišná y procedía de la provincia de Forlì-Cesena en la región italiana de Emilia Romagna. Su travesía posee un claro objetivo místico que lo lleva a viajar hacia Tierra Santa en 1488, coincidiendo con Mešulam de Volterra ${ }^{6} \mathrm{y}$, a diferencia de éste, sus vivencias están más cercanas al pueblo que al poder. Sin embargo, ambos comparten un mismo modo de proceder en sus relatos y es el de la descripción, no únicamente de sus experiencias personales propias ni de las comunidades judías, sino en el del retrato o cuadro de aquellos grupos no judíos con los que se encuentran.

A partir de aquí y partiendo de las consideraciones y destinatarios a los que van dirigidas las cartas en las que describen su viaje, la de Mešulam

\footnotetext{
${ }^{5}$ DAVID, «Jewish Travelers from Europe to the East, 12th-15th Centuries», Miscelánea de Estudios Árabes y Hebraicos, Sección Hebreo 62 (2013) págs. 11-39: 31. Véase la traducción inglesa de E. N. AdLER, Jewish Travellers in the Middle Ages. 19 Firsthand Accounts (New York 1930) págs. 156-208; al español, J. R. Magdalena Nom DE Déu, Relatos de viajes y epístolas de peregrinos judios a Jerusalén (1481-1523) (Sabadell 1987) págs. 11-17 y 41-94, así como los estudios de A. Veronese, Una famiglia di banchieri ebrei tra XIV e XVI secolo: i da Volterra. Reti di credito nell'Italia del Rinascimento (Pisa 1998) y Meshullam da Volterra, Viaggio in Terra d'Israel (Rimini 1989).

${ }^{6}$ DAVID, «Jewish Travelers from Europe», págs. 33-34. Para un recorrido en torno a los manuscritos, traducciones y estudios de su obra, véanse las páginas 34-37 del artículo citado aunque destacamos las siguientes contribuciones: A. David y J. R. Magdalena Nom DE DÉu, De Italia a Jerusalén. El viaje de rabí Obadyah de Bertinoro, 1486-1488 (Granada 2013); Magdalena, Relatos de viajes y epístolas, págs. 21-28 y 101-147; A. Neubauer, «Selection from Two Letters Written by Obadia da Bertinoro in the Years 1488 and 1489», Miscellany of Hebrew Literature 1 (1872) págs. 113-150; G. TAMANI, «La diffusione del commento alla Misnah di Ovadyah Yare da Bertinoro», en 'Ovadyah Yare da Bertinoro e la presenza ebraica in Romagna nel Quattrocento, ed. G. BusI (Torino 1989) págs. 47-56; A. TOAFF, «Ovadiah da Bertinoro nella realta italiana del suo tempo», en L'interculturalità dell'ebraismo, ed. M. Perani (Ravenna 2004) págs. 257-268.
} 
-y pese a algunos de sus pasajes críticos- más dialogante y comprensivo con otras comunidades religiosas y la segunda, de 'Obadiá, de carácter privado y mucho más crítica con aquellas, se puede observar la alteridad en sus vivencias y relatos. De hecho, el mismo 'Obadiá es consciente de la multiplicidad de culturas que llega a encontrar en el Mediterráneo en su viaje y así lo plasma a su llegada a El Cairo:

[...] y es una ciudad bulliciosa, y en su interior se encuentran gentes de todas las lenguas de los gentiles. Y puesto que se asienta entre dos mares, entre el mar Rojo y el mar Grande -que es el mar de Alejandría- todos los mercaderes del país de India y Kus y tierras del Preste Juan vienen camino del mar Rojo a El Cairo para vender mercaderías que vienen desde Francia, Alemania, Italia y Togarma, camino del mar Grande a Alejandría, hasta El Cairo?

En otros casos y como apuntará Volterra, pese a la multiplicidad de culturas y religiones con las que se topa en su viaje, a veces las diferencias parecen insalvables con sus propios correligionarios o tendrán tanto en común con los musulmanes que incluso los viajeros se sorprenden:

[...] Y por último, los que más apreciamos: en Alejandría hay como unos 60 propietarios de casas judíos, y no hay ningún caraíta ni samaritano, sino rabanitas. Y su costumbre es como la costumbre de los ismaelitas en el vestir; y en la sinagoga se sientan sobre el suelo, no llevan calzados y no entran en la sinagoga con zapatos, sino con calcetines ${ }^{8}$.

[...] igualmente hacen los judíos como los ismaelitas en todo el país de la gobernación del sultán; no tienen cama ni mesa ni silla ni lámpara, y comen, beben y duermen siempre sobre el suelo, y hacen todas las cosas en el suelo y posición sedente?

\footnotetext{
${ }^{7}$ David y Magdalena, De Italia a Jerusalén, pág. 82. A lo largo del artículo mantenemos las traducciones de todos los textos tal y como se presentan en las versiones al español trabajadas.

${ }^{8}$ Magdalena, Relatos de viajes y epístolas, pág. 51.

${ }^{9}$ Magdalena, Relatos de viajes y epístolas, pág. 49.
} 


\section{La Alteridad en los teXtos: la PERCEPCión de MeŠUlam de} Volterra y 'Obadiá de Bertinoro

Con el objetivo de mostrar de manera ordenada la alteridad que exhiben los relatos de estos viajeros judíos desde Europa hasta Oriente, hemos considerado conveniente fijar nuestra atención en aquellos puntos fundamentales que comparten y a los que dedican pensamientos, reflexiones e impresiones en sus narraciones y que dividiremos en varios epígrafes:

\subsection{Alejandría: la ciudad comercial}

Ambos viajeros judíos, a su paso hacia Tierra Santa, se detuvieron en Alejandría ${ }^{10}$. Ya fuera su viaje por motivos comerciales o religiosos, lo cierto era que esta ciudad resultaba ser una de las paradas obligatorias en las travesías cuando se seguía la ruta sur. En el siguiente extracto, Mešulam de Volterra describe de manera pormenorizada la ciudad haciendo referencia a algo que a otro autor del siglo XII Benjamín de Tudela $^{11}$, ya le había asombrado y es que la ciudad poseyera cisternas que

\footnotetext{
${ }^{10}$ Sobre esta ciudad, véase P. BALTA, «El cosmopolitismo de Alejandría», Cuadernos del Mediterráneo 5 (2005) págs. 141-152; L. J. KleinstaDT-RoHR, «Alejandría, Jerusalén, Roma: Modelos de ciudad», Debats 54 (1995) págs. 4-12; J. Marlowe, The Golden Age of Alexandria: From its Foundation by Alexander the Great in 331 BC to its Capture by the Arabs in 642 AD (London 1971), y F. Roldán CASTRO, «La ciudad de Alejandría en el "Atar Al-Bilad” de Al-Qazwini», Philologia hispalensis 14:2 (2000) págs. 345-361.

${ }^{11}$ El viaje de este autor se produce entre 1159 y 1173 y se recoge en su Sefer Masa 'ot o 'Libro de Viajes'. Parece que respondería a un propósito comercial aunque la información que ofrece se focaliza, más que ningún otro, en las comunidades judías con las que tiene contacto. De esta manera, proporciona unas notas útiles acerca del número de judíos en cada comunidad; personalidades destacadas; líderes; nivel cultural; condición social y económica; oficios a los que se dedican, entre otros y este hecho diferencia esta obra de la de los otros dos autores. Por tanto, constituiría una guía para el nuevo viajero judío que desearía trasladarse a otros núcleos teniendo ya un conocimiento previo de estos. Sin embargo, también se apunta a que su interés podría ser puramente curioso y su viaje se debiera a que quisiera conocer el estado de estas comunidades en el Mediterráneo y Oriente. Véase DAVID, «Jewish Travelers from Europe», págs. 13-21. Destacamos aquí la traducción inglesa de M. N. AdLER, «The Itinerary of Benjamin of Tudela. Critical Text, Translation and Commentary», Jewish Quarterly Review 16:3-4 (1904), págs. 453-473 y
} 
hacían que sus cimientos estuvieran huecos. Además, es interesante el hecho de que Volterra la compare con las ciudades de Roma o Florencia en un intento por acercar algo desconocido o nuevo a otro algo que es bien conocido por él o por sus hipotéticos lectores:

Ese mismo día bajé a Alejandría, [que] está al lado derecho, en la llanura: el mar está en su interior. Y hay torres sobre el mar y un obelisco como el de Roma, pero no tan grande. Cuando entras en la costa de Alejandría, junto a la ciudad, encuentras una hermosa ciudadela de 32 torres; y la muralla tiene un espesor de 10 codos, va de torre en torre y se extiende por la ciudad ocultamente [...] Y jamás vi una ciudadela tan hermosa como ella; es nueva de hace tres años. Alejandría es grande como Florencia, toda construida en calles; y las murallas de la ciudad son altas y hermosas, pero la ciudad está toda devastada y hay muchas más [casas] destruidas que las que se mantienen en pie. Las casas son bonitas, y en cada casa hay un patio con blancos pavimentos, y un árbol en medio del patio y los aljibes dentro del patio: En cada casa hay dos aljibes, uno para las aguas nuevas y otro para las aguas viejas, ya que el Nilo sube cada año en el mes de agosto y riega toda Alejandría. Ellos limpian las cisternas vacías y las aguas entran en su interior, pues Alejandría está hueca por debajo debido a las citadas cisternas ${ }^{12}$.

Además, Volterra se detiene en la vestimenta tanto de hombres como de mujeres:

Escudriñé Alejandría y sus cosas y vi que todas ellas son diferentes [a las de Occidente]. Las mujeres ven y no son vistas, pues llevan una pañoleta negra sobre sus rostros y en ella hay pequeños agujeros; y llevan en sus cabezas una mitra de papel plegada en varios dobleces, encolada

715-733; al español de J. R. Magdalena Nom de Déu, Libro de Viajes de Benjamín de Tudela (Barcelona 1982) así como los estudios de Z. ANKori, «Viajando con Benjamín de Tudela: nueva solución a algunos problemas antiguos», en Congreso Internacional Encuentro de las Tres Culturas, coord. C. CARrete Parrondo (Toledo - Tel-Aviv 1988) págs. 11-28; S. BERger, Translation between Language and Culture. Benjamin of Tudela's Travels in Yiddish (Amsterdam 1691) (Amsterdam 2005); P. E. ForNACIARI, «La percezione del mondo dalmata e slavo in Beniamino da Tudela», Itineraria 3-4 (2004-2005) págs. 57-72; D. JАСОВY, «Benjamin of Tudela and his 'Book of Travels'», en Venezia incrocio di culture. Percezioni di viaggiatori europei e non europei a confronto, eds. Klaus Herbers y Felicitas Schmieder (Roma 2008) págs. 135-164.

${ }^{12}$ Magdalena, Relatos de viajes y epístolas, págs. 49-50. 
y, sobre ella, una pañoleta blanca que llega hasta sus tobillos y cubre su nariz ${ }^{13}$.

Los ismaelitas visten asimismo ropajes de lino, se sientan siempre sobre las esteras o sobre los tapetes y caminan sin calzados y sin calcetines, aunque van con calceta de lino hasta la mitad de la pantorrilla ${ }^{14}$.

La reflexión que hace 'Obadiá en torno a Alejandría difiere por varios motivos. En primer lugar, presta mucha más atención a cuestiones relativas a la población que al conjunto estético aparente de la ciudad, al que únicamente dedica unas líneas. En cambio, su énfasis está dedicado al hecho de que una gran parte de la población enferma y muere por el ambiente respirado allí. Tal y como comentamos anteriormente, 'Obadiá se encuentra mucho más cercano a la población que Mešulam por su condición social, lo que provoca que la percepción de ambos no coincida en algunas ocasiones. Además, anota la presencia cristiana a través de sus cónsules con detalle, lo que revela importante información acerca de las cuestiones diplomáticas y económicas de la ciudad:

Alejandría es una ciudad muy grande, y está circundada por murallas y el mar la rodea. Y aunque dos tercios son desierto y desolación y muchas casas están deshabitadas, su panorama demuestra que fue muy bonita. Y los patios habitados que hay en ella están todos pavimentados con piedras, como mosaico, y árboles de membrillos y palmeras en el centro. Todas las casas son, en general, hermosas y grandes. Hay pocas personas en Alejandría debido al fuerte viento que se sopla en ella desde hace unos cuantos años. Y en particular, quien no se habitúa a su aire y prolonga su estancia en ella, dicen que morirá o enfermará, sin duda. Y la mayoría de habitantes están afectados de aturdimiento. A ella vienen de todos los confines del país para el comercio. Y hay allí cuatro cónsules de países cristianos: venecianos, genoveses, catalanes y anconitanos; y a su criterio se quedan y viajan todos los mercaderes de todas las lenguas de los cristianos que vienen allí para comerciar ${ }^{15}$.

\footnotetext{
${ }^{13}$ Magdalena, Relatos de viajes y epístolas, pág. 48.

${ }^{14}$ Magdalena, Relatos de viajes y epístolas, pág. 49.

${ }^{15}$ David y Magdalena, De Italia a Jerusalén, pág. 78.
} 


\subsection{Jerusalén: la ciudad santa}

En las travesías de Europa a Oriente, Jerusalén siempre se contemplaba como el destino principal por su carácter de ciudad santa ${ }^{16}$. Sin embargo y pese a los esfuerzos de estos dos viajeros por llegar a ella, la visión que transmiten resulta desoladora y decepcionante, haciendo referencia de forma unánime a los pocos habitantes judíos que todavía viven allí:

Cuando vi su destrucción... Y he aquí que Jerusalén no tiene murallas..., sino tan sólo un tramo por donde entré. Y a pesar de que está toda derruida...en ella hay 10.000 propietarios de casas ismaelitas y como unos 250 propietarios de casas judíos ${ }^{17}$. [Mešulam de Volterra].

Jerusalén está arruinada y desolada en su mayor parte, y no hace falta decir que no la circunda muralla. La gente que hay en ella -según me contaron- son como unos 4.000 propietarios de casas y de entre los judíos no han quedado hoy en ella más que 70 propietarios de casas, de los más pobre de la población, que no tienen sustento ${ }^{18}$. ['Obadiá de Bertinoro].

Incluso con anterioridad y de acuerdo al relato de Benjamín de Tudela, en la ciudad siglos atrás habitaban pocos judíos:

Jerusalén [que] es una pequeña ciudad, fortificada bajo tres murallas... Hay en Jerusalén cuatro puertas: la puerta de Abraham, la puerta de David, la puerta de Sión y la puerta de Josafat, es decir, la puerta de Yehosafat, delante del Templo que había en los días de antaño. Hay como unos 200 judíos habitando al pie de la Torre de David ${ }^{19}$. [Benjamín de Tudela].

\footnotetext{
${ }^{16}$ Véase F. CARDInI, El mundo de las peregrinaciones: Roma, Santiago, Jerusalén (Barcelona 1999) págs. 321-375; J. WiLkinson, Jerusalem Pilgrims before the Crusades (Warminster 1977); J. Wilkinson, J. Hill y W. F. RYAN, Jerusalem Pilgrimage 10991185 (London 1988); F. E. Peters, Jerusalem: The Holy City in the Eyes of Chroniclers, Visitors, Pilgrims, and Prophets from the Days of Abraham to the Beginnings of Modern Times (Princeton 1985); H. F. M. Prescott, Jerusalem Journey: Pilgrimage to the Holy Land in the Fifteenth Century (London 1954); N. Schur, Jerusalem in Pilgrims' and Travellers' Accounts. A Thematic Bibliography of Western Christian Itineraries 13001917 (Jerusalem 1980).

${ }^{17}$ Magdalena, Relatos de viajes y epístolas, pág. 76.

${ }^{18}$ David y Magdalena, De Italia a Jerusalén, pág. 98.

${ }^{19}$ Magdalena, Libro de viajes, pág. 172. El mapa de Jerusalén de un Salterio (ca. 1200) conservado en La Hague Koninklijke Bibliotheek, 76 F 5, coincide plenamente con
} 
Esta sensación de desolación plasmada anteriormente se extenderá en el tiempo y será común entre los autores pues, en 1521, Mošé Basola, un rabino procedente de Italia ${ }^{20}$, se refiere a la ciudad de la siguiente manera:

Jerusalén... allí me rasgué las vestiduras y también lloré por la ciudad destruida y desolada, sin reconstruir... Y a pesar de que Jerusalén está destruida y asolada, todavía se reconoce en ella un poco de la mínima parte de su hermosura en general... Entre todos [los judíos] hay como unos 300 propietarios de casas... Los que colectan caridad son más de 200 almas $^{21}$.

A pesar de que hayan pasado algunos años desde 1488, cuando 'Obadiá visitó la ciudad, aun puede apreciarse mediante este texto que la situación de la comunidad judía no había cambiado sustancialmente ya que una gran parte de las familias vivían de la caridad, según apunta Basola, ya en la primera mitad del siglo XVI.

\subsection{De judío a judio: diferencias culturales}

Pese a profesar todos el judaísmo, las diferencias culturales entre los viajeros y las comunidades que visitan son evidentes para ellos al poseer estos últimos una cultura oriental y no occidental. Así describen Mešulam y 'Obadiá los hechos que les provocan un mayor asombro cuando se reúnen con estos judíos orientales a compartir mesa en relación a la comida y al vino:

$\mathrm{Y}$ cuando quieren agasajar a alguien, traen vino de pasas, que es mil veces mucho más fuerte que la malvasía, y hay que beber dos veces antes

la descripción de Benjamín de Tudela (véase el recurso online en http://jnul.huji.ac.il/dl/ maps/jer/html/jer424.htm).

${ }^{20}$ Véase R. Lamdan, Rabbi Moshe Basola. His Life and Work (Tel-Aviv 1983 [en hebreo]) y «Two Writings by R. Moshe Basula», Michael 9 (1985) págs. 171-193 [en hebreo]; A. David y A. Veronese, A Sion e a Gerusalemme. Viaggio in Terra Santa (1521-1523) (Firenze 2003); A. DAVID, «From Italy to Jerusalem. R. Moses Basola and his Travelogue in 1521-1523», Miscelánea de Estudios Árabes y Hebraicos, Sección

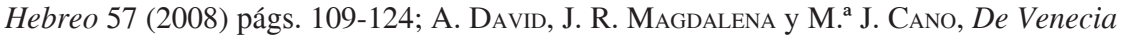
a Tierra Santa. El viaje de rabí Moseh Basola 1521-1523 (Granada 2014).

${ }^{21}$ David, Magdalena y Cano, De Venecia a Tierra Santa, págs. 94; 100 y 103. 
de que te den de comer nada, sino tan sólo unas frutas. En resumen: tienes que beber ante todos reunidos. Y quién bebe dice al forastero: « $i E n$ tu honor!», y toma una fruta y la pone en su mano, diciendo: «iPura vida y salud!»Y has de beber, tanto tú como los demás, hasta que pasan dos horas antes de comer; y habrás bebido tantas veces cuantas beben también ellos. Si no bebes haces un gran desprecio al dueño de la casa. Y a mí me pasó varias veces esta cosa, pero como la sabía de antemano, antes de ir hice acuerdo con ellos diciendo que no podía beber, pues tenía una grave enfermedad en mi cuerpo, de manera que me vi libre de esta libación; a pesar de ello mi sirviente Rafael fue mi sustituto de qué modo que [ya] no distinguía entre el maldito Amán y el bendito Mardoqueo. Y para mí fue la libación como ley sin obligación, igracias a Dios vivo! ${ }^{22}$. [Mešulam de Volterra].

Y éste es el asunto del festín que acostumbran hacer los judíos en todos los países de ismaelitas, en sábado: se sientan en círculo sobre tapetes y no tienen entre ellos mesa alguna, sino un pequeño mantel extendido sobre el tapete, y ante ellos está la bebida. Y traen toda clase de frutas que encuentran en esa época y las ponen sobre el mantel; y el dueño de la casa toma un vaso de vino y lo bendice y lo bebe todo; y el copero toma este vaso de la mano del propietario de la casa y sirve bebida en él a cada invitado de la reunión: uno tras otro, en orden, cada uno bebe un vaso lleno de vino ${ }^{23}$. ['Obadiá de Bertinoro].

Después, el dueño de la casa toma uno, dos o tres gajos de las frutas y bebe un segundo vaso, y todos los invitados dicen: « $i$ Salud y vida!» Y quien se sienta a su lado toma también tras él algo de fruta, y el copero le da un vaso de vino, y dice: «¡Por tu alegría!», y le dicen; «iSalud y vida!» Y así todos los comensales, uno a uno. Luego cogen otra clase de frutas y combinan un tercer vaso con ellas, y hacen según este orden hasta que han bebido por lo menos seis o siete vasos. A veces beben como aspirando, pues traen mandrágoras -y son las que comentó el rabí Šelomoh Yiṣhaq- que llaman en lengua árabe jazmín, que es un árbol que no da más que flores, las cuales tienen buen aroma y son muy calientes, y lo perfuman con dichas mandrágoras y beben un vaso de vino. En esas comarcas el vino es muy fuerte, especialmente en Jerusalén, y lo beben vivo. Y después de haber bebido los vasos que les place, traen un gran

\footnotetext{
${ }^{22}$ Magdalena, Relatos de viajes y epístolas, pág. 58.

${ }^{23}$ David y Magdalena, De Italia a Jerusalén, pág. 75.
} 
lebrillo lleno de manjares y viandas y cada uno pone su mano y toma del lebrillo lo que su corazón desea [...] Y bebí y me embriagué con él. En todo país de ismaelitas hay la costumbre, para los judíos, que todos van a la casa del baño la víspera del sábado, y a su regreso, las mujeres traen ante ellos vino, y beben mucho; y después traen el guiso que prepararon para la cena, y comen desde que es de día hasta que oscurece ${ }^{24}$. ['Obadiá de Bertinoro].

Sin embargo, también se muestran sorprendidos de acuerdo a la descripción ofrecida de otras sectas judías como los caraítas o los samaritanos e incluso 'Obadiá llega a compararlas y se atreve a exponer cuál de ellas le parece mejor. En el siguiente extracto, Mešulam describe a los caraítas a los que contrapone con los «buenos judíos» que, como nosotros -refiriéndose a él y aludiendo al ellos y nosotros en concepto de alteridad y contraposición-, únicamente poseen unas cuantas sinagogas:

Y ya sabes que los caraítas cumplen con la Ley Escrita, y asimismo los samaritanos toman un poco de la Ley Escrita, mas practican idolatrías y su escritura es distinta de todas las escrituras, y no poseen la 'alef, ni la he', ni la 'ayin, ni la sade ni la bet ni la het; como si dijeses Ya'aqob: Yaqob; Yișhaq dicen: Yisaq como les parece. Y sus Pentateucos y todos sus libros están [escritos] con su escritura. Y anualmente suben al monte Gerizín, tres veces al año, y allí tienen un altar y ponen una paloma de oro y la ofrecen sobre el altar. Y no van a Jerusalén y no habitan allí puesto que ellos dicen que el monte Gerizín es el monte [del Templo] de Jerusalén, e inmolan un cordero y no lo comen. Están solos y tienen una sinagoga exclusivamente para ellos; observar el sábado hasta la mitad del día, y después lo profanan. También los caraítas tienen sinagogas para ellos solos. Los buenos judíos que observan la Ley Escrita y la Tradición Oral -que ellos, como nosotros, también están juntos- tienen seis sinago$\operatorname{gas}^{25}$. [Mešulam de Volterra].

Y los samaritanos no tienen más que el Pentateuco, y no tienen nuestra escritura santa, sino otra escritura. Y escribió R. Mošeh ben Maymon que es escritura hebrea con la que los israelitas escribían en un principio, antes de que fuesen exiliados a Asiria, como se cita en la Gemara, en Sanhedrín. Pero tienen Lengua Santa, como nosotros, aunque la diferencian un poco en la lectura, porque la escritura es distinta de la nuestra. Y en todas

\footnotetext{
${ }^{24}$ David y Magdalena, De Italia a Jerusalén, págs. 75-76.

${ }^{25}$ Magdalena, Relatos de viajes y epístolas, pág. 60.
} 
partes de la Torá, en lugar del Nombre de Yud-he', está escrito 'ašima'. Y ellos son odiados por los judíos, debido a que ellos ofrecen [sacrificio] y queman incienso en el monte Gerizín -y con nosotros viajaron desde El Cairo muchos de ellos para ir al monte Gerizín- para el sacrificio de Pésah, pues en él tienen un santuario. No guardan el sábado más que desde la medianoche del viernes hasta la medianoche del sábado... Los samaritanos son más ricos que todos los demás judíos que hay en El Cairo, y hacen el trabajo de los grandes ministros que hay en el Cairo, y son sus tesoreros y agentes [...] Los caraítas son más ricos que los judíos rabanitas. Pero la cualidad natural de los judíos que hay en tierra de ismaelitas es mostrarse a sí mismos pobres, y siempre van como indigentes y depreciados y encorvados ante los ismaelitas. Y no son filántropos, ni jamás hacen bien al prójimo, y no se estiman entre sí y cada uno busca su propio bien. En esto es mejor la secta de los caraítas que la comunidad de los judíos rabanitas, pues ellos se hacen favores entre sí, y también se mezclan con los rabanitas y les hacen favores ${ }^{26}$. ['Obadiá de Bertinoro].

\subsection{Otras comunidades: musulmanes y cristianos}

Es inevitable que los viajeros se detuvieran en describir pormenorizadamente todas aquellas cuestiones relativas a otras comunidades, como la de musulmanes -a los que llaman ismaelitas con frecuencia- y la cristiana. A los primeros, los retratan de la siguiente manera en sus costumbres:

Los ismaelitas se asemejan a los camellos y a las bestias, pues el camello va sin herraduras, también ellos sin calzados; el camello se tiende y come en el suelo, también ello se tienden y comen en el sueño, sin mantel, más que con un pellejo rojo; el camello duerme con su silla, así ellos duermen y se acuestan sobre sus ropas, y jamás se quitan de sí mismos sus vestidos por las noches ${ }^{27}$. [Mešulam de Volterra a su paso por Alejandría].

Y si preguntáis: ¿Cuáles son sus costumbres [de los ismaelitas]? Y ¿qué hay que hacer? Cuando llegues a esos lugares tienes que descalzarte muy rápidamente, sentarte en el suelo y tus pies encogidos bajo de ti, [de modo] que tus piernas no asomen nada hacia afuera y no te mantengas

\footnotetext{
${ }^{26}$ David y Magdalena, De Italia a Jerusalén, págs. 83-84 y 86-87.

${ }^{27}$ Magdalena, Relatos de viajes y epístolas, pág. 49.
} 
en absoluto sobre tus pies; y [hay que] comer en el suelo, y que no caiga al suelo ningún [pedazo] de pan que no recojas, y no comas hasta que no hayas alzado el pan sobre tu cabeza, y [hay que] dar a los comensales de todo lo que comas, incluso a los que no comen contigo; no te quites jamás las vestiduras: duerme con ellas por la noche [...] Igualmente, si no tienes más que pan y un vaso de vino, y otro viene y te lo toma, y come y bebe, deja hacer, pues toman incluso de los príncipes y no hay que responder ni decir nada. Es también su costumbre, cuando se sientan a comer, sentarse en círculo y todos comen en un plato, y el siervo con su dueño, y pone las manos dentro de la jofaina, en vez del cucharón, y no ponen ante ellos ni mantel ni cuchillo ni sal, y no se limpian jamás las manos, sino después de la comida se lavan rápidamente sus manos hasta el antebrazo ${ }^{28}$. [Mešulam de Volterra a su paso por Gaza].

Sin embargo, el mismo Mešulam que había descrito a los musulmanes en los párrafos anteriores, compara a estos con los judíos del lugar en un intento por clarificar que unos y otros no eran tan distintos en su manera de comer, en cuestiones relativas al matrimonio como el documento de repudio o guet, o asuntos rituales como el ayuno:

Los ismaelitas -y asimismo los judíos de lugar- son como puercos en sus comidas, pues todos comen en un recipiente, con los dedos, sin mantel, como hacen en Egipto, pero son limpios en sus vestidos [...] toman veinte o treinta mujeres, según todo lo que deseen, y no las ven hasta que está[n] en sus casas ${ }^{29}$. [A su paso por Jerusalén].

Los hombres dan la dote a las mujeres, y desde ese día en adelante el hombre no debe darle más que de comer; y los vestidos y todos los otros asuntos [se] los procura ella por ella misma. También, cuando está en cinta, los ismaelitas no la tocan hasta dos meses después de que ha parido, pues es un gran pecado en su religión derramar semilla en vano, incluso con sus mujeres. La esposa debe alimentar y vestir a todos los hijos e hijas. Por eso todas son afamadas nodrizas. Y cuando no quieren permanecer con su esposo, van al gobernador de la ciudad y dicen que el marido no les da comida para sus dientes, y las creen en sus palabras. Es necesario que el marido les conceda rápidamente el documento de repu-

\footnotetext{
${ }^{28}$ Magdalena, Relatos de viajes y epístolas, pág. 70.

${ }^{29}$ Magdalena, Relatos de viajes y epístolas, pág. 80.
} 
dio, pues los ismaelitas, como los judíos, le dan documento de repudio ${ }^{30}$. [En Jerusalén].

Cuando entran en la mezquita se lavan. Cada mezquita tiene una fuente para que puedan lavarse cinco veces al día. Y tienen su fiesta el viernes, pero no guardan fiesta son dos horas, mientras están en sus oraciones. Tienen dos festividades al año, y ayunan 30 días seguidos una vez al año y su ayuno es como el ayuno de los judíos. Y les ordenó a ellos Él mismo que nos mandó nosotros como digno de elogio, que se prosternasen ante la vanidad $^{31}$. [En El Cairo].

Comparando los textos de Volterra con los de otro autor mencionado anteriormente, Benjamín de Tudela, observamos que éste va más allá y señala puntos de conexión entre los judíos y los musulmanes en lo referente a sus casas de oración y convivencia aproximadamente tres siglos atrás:

[Los judíos] hicieron ante su sepulcro [de Esdras] una gran sinagoga. $\mathrm{Al}$ otro lado los ismaelitas hicieron una casa de oración por el gran amor que le profesan y por eso aprecian a los judíos y van allí los ismaelitas a rezar $^{32}$. [Benjamín de Tudela a su paso por Kufa].

Asimismo los notables ismaelitas acuden allí a rezar por su gran amor al profeta Ezequiel. Llaman a aquel lugar dar malihan ['casa salerosa'] y todos los árabes acuden allí a rezar ${ }^{33}$. [Benjamín de Tudela en Kafri, ciudad cercana a Bagdad].

\subsection{Convivencia entre grupos religiosos}

Un documento relevante son las apreciaciones que los viajeros realizan en sus cuadernos sobre la convivencia entre grupos religiosos que habitan juntos en las diferentes localizaciones que visitan. De esta manera, no únicamente obtenemos un relato de primera mano sobre sus impresio-

\footnotetext{
${ }^{30}$ Magdalena, Relatos de viajes y epístolas, pág. 80.

${ }^{31}$ Magdalena, Relatos de viajes y epístolas, pág. 61.

${ }^{32}$ Magdalena, Relatos de viajes y epístolas, pág. 185.

${ }^{33}$ Magdalena, Relatos de viajes y epístolas, pág. 185.
} 
nes sino que se puede llegar a conocer fielmente el modo en que conviven estas comunidades y, sobre todo, la posición de los judíos entre ellas. De entre todas, destacan los grupos musulmanes y los cristianos aunque también hacen referencia, casi anecdótica, a otros minoritarios aunque con los musulmanes serán especialmente duros en sus impresiones:

Los ismaelitas son malos y pecadores contra Dios, no tienen fe en sus cosas y se comportarían mal si no fuese por temor a [la autoridad] real ${ }^{34}$. [Mešulam de Volterra en El Cairo].

A los judíos o a los cristianos les está prohibido alzar su segundo dedo, ya que pueden obligarles -Dios no lo quiera- a ser ismaelita, o lo matan. También les está prohibido subir a sus mezquitas ${ }^{35}$. [Mešulam de Volterra en El Cairo].

Puede apreciarse la relación de unos grupos con otros así como el hostigamiento sufrido por los cristianos a manos de los musulmanes, tal y como relata 'Obadiá a su paso por la ciudad de Alejandría:

Cada noche, los cristianos que se encuentran en Alejandría, han de reunirse y encerrarse en sus casas, y los ismaelitas les cierran por fuera y cada mañana les abren. Y lo mismo el viernes desde medianoche hasta la otra tarde, cuando los ismaelitas se congregan en la casa de oración, han de reunirse los cristianos en casa y les cierran. Y el cristiano que es encontrado en ese momento fuera es detenido ${ }^{36}$.

Sin embargo, la situación para 'Obadiá, ya en el siglo XV, cambia en Jerusalén donde describe la convivencia de los judíos con los musulmanes en estos términos:

Ciertamente, no hay ningún destierro para los judíos este lugar, entre los ismaelitas. He ido por todo el país, a lo largo y a lo ancho, sin que nadie dijese esta boca es mía, y se compadecen mucho del hombre forastero y mucho más de quien no conoce la lengua, y aunque vean a muchos judíos juntos, no les acosan en absoluto ${ }^{37}$.

\footnotetext{
${ }^{34}$ Magdalena, Relatos de viajes y epístolas, pág. 61.

${ }^{35}$ Magdalena, Relatos de viajes y epístolas, pág. 61.

${ }^{36}$ David y Magdalena, De Italia a Jerusalén, pág. 78.

${ }^{37}$ David y Magdalena, De Italia a Jerusalén, pág. 99.
} 
Benjamín de Tudela, en Bagdad y en la que época en la que realiza su viaje, expone un panorama muy similar al de 'Obadiá en su impresión anterior:

Hay allí en Bagdad como unos cuarenta mil judíos israelitas y permanecen en calma, tranquilidad y honor bajo el poder del gran rey ${ }^{38}$.

O en Adén:

[...] allí hay israelitas sobre quienes no pesa yugo de gentiles. Poseen ciudades y torres en las cumbres de las montañas, bajan a la tierra de la llanura que llaman Nubia, dominio de cristianos [...] los judíos hacen guerras contra ellos y toman presa y botín $[\ldots]$ nadie puede guerrear con ellos ${ }^{39}$.

Un hecho interesante es que se describan otras comunidades minoritarias, tales como los drusos y los cusitas, a los que sí se refiere Benjamín de Tudela en su 'Libro de Viajes'. La de los drusos es cercana a los relatos maravillosos pero es destacable su indicación de las buenas relaciones que estos tienen con los judíos:

Hay unas gentes que están en guerra con los habitantes de Sidón: es el pueblo conocido como drusos, son paganos y no tienen religión alguna [...] no tienen príncipe ni rey que les gobierne, puesto que por sí mismos se asientan entre los montes y los peñascos [...] entregados a la depravación, poseen a sus hermanas y el padre posee a su hija $[\ldots]^{40}$.

Hay [en Aswan] entre ellos unas gentes [los cusitas] que son como bestias: comen las hierbas que hay sobre la orilla del Nilo y en los campos, andan desnudos y no tienen conocimiento como los demás hombres: yacen con sus hermanas y con quien encuentran... ellos son los esclavos negros hijos de $\mathrm{Cam}^{41}$.

\footnotetext{
${ }^{38}$ Magdalena, Libro de Viajes, pág. 181.

${ }^{39}$ Magdalena, Libro de Viajes, pág. 194.

${ }^{40}$ Magdalena, Libro de Viajes, pág. 169.

${ }^{41}$ Magdalena, Libro de Viajes, pág. 195.
} 


\section{CONClusión}

Aunque los viajeros hacen unas descripciones geográficas y urbanísticas similares, se puede apreciar una nítida diferenciación entre la concepción del yo -judíos rabanitas occidentales-, del otro -gentiles, tanto musulmanes como cristianos- y del nosotros -judíos en general-. Se observa la percepción de la existencia de dos sistemas de vida, el oriental, claramente islamizado en sus usos y costumbres, y el occidental, de cultura cristiana. Eso queda patente en los matices diferenciadores de los relatos de los viajeros italianos y en los extractos de Benjamín de Tudela siglos atrás y para el que, siendo originario de territorios de cultura arabo-islámica, las costumbres de los judíos del Medio Oriente no le son completamente ajenas. Lo más importante es que de los relatos de estos viajeros se deduce que la convivencia entre judíos y musulmanes era un hecho, lo que no parece que sucediera con los cristianos ya que en los territorios musulmanes estos formaban parte de las minorías.

Recibido: $22 / 09 / 2015$

Aceptado: 22/11/2015 